\title{
Intrapericardial diaphragmatic hernia and atrial septal defect in adults
}

\author{
Nejat Sariosmanoğlu, MD, Eyüp Hazan, MD, Kivanç Metin, MD, Hakki Kazaz MD, and Öztekin Oto, MD, \\ İzmir, Turkey
}

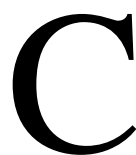

ongenital diaphragmatic herniation of the intestines into the pericardial cavity is an extremely uncommon condition in adults. Its association with atrial septal defect (ASD) has been reported in only 2 cases. ${ }^{1,2} \mathrm{We}$ recently encountered this condition in an adult patient.

\section{Clinical Summary}

A 29-year old man was referred to our clinic because of dyspnea on effort, slight limitation of physical activity, and easy fatigability. On physical examination, a grade $2 / 6$ ejection-type systolic murmur was present along the left sternal border. The second heart sound was split and fixed. A preoperative chest $\mathrm{x}$ ray film showed cardiomegaly with a prominent pulmonary arterial segment and increased pulmonary vascularity. No sign of a diaphragmatic hernia was evident. Echocardiography revealed a 14-mm secundum-type ASD and reversed septal wall motion mimicking a septal aneurysm. The ASD was diagnosed by catheterization with a pulmonary/systemic flow ratio of $2: 1$.

The patient was subjected to elective closure of the ASD via a median sternotomy. After opening the pericardium, we found that the pericardial cavity was filled by the small intestines and omentum, which protruded through a defect at the posterior pericardium. These organs were covered with a very thin, completely transparent, colorless membrane that represented the true hernia sac and could be readily distinguished through the membrane. The membrane changed to a thin muscular fibrotic structure at the base of the sac. There was a small opening $(<10 \mathrm{~mm}$ in diameter $)$ in the sac at the right posterior aspect of the pericardial cavity (Figure 1). On digital examination, the intrapericardial defect extended into a small slitlike hole at the anterior portion of the diaphragm. There was no sign of strangulation or ischemia of the intestines. The

From Dokuz Eylül University School of Medicine, Department of Thoracic and Cardiovascular Surgery, Izmir, Turkey.

Received for publication March 30, 2001; accepted for publication April 8, 2001

Address for reprints: Nejat Sariosmanoğlu, MD, Dokuz Eylül University School of Medicine, Department of Thoracic and Cardiovascular Surgery, 35340 İzmir, Turkey (E-mail: deucvs@medscape.com).

J Thorac Cardiovasc Surg 2002;123:353-4

Copyright @ 2002 by The American Association for Thoracic Surgery $0022-5223 / 2002 \$ 35.00+0 \quad \mathbf{1 2 / 5 4 / 1 1 6 4 6 7}$

doi:10.1067/mtc.2002.116467

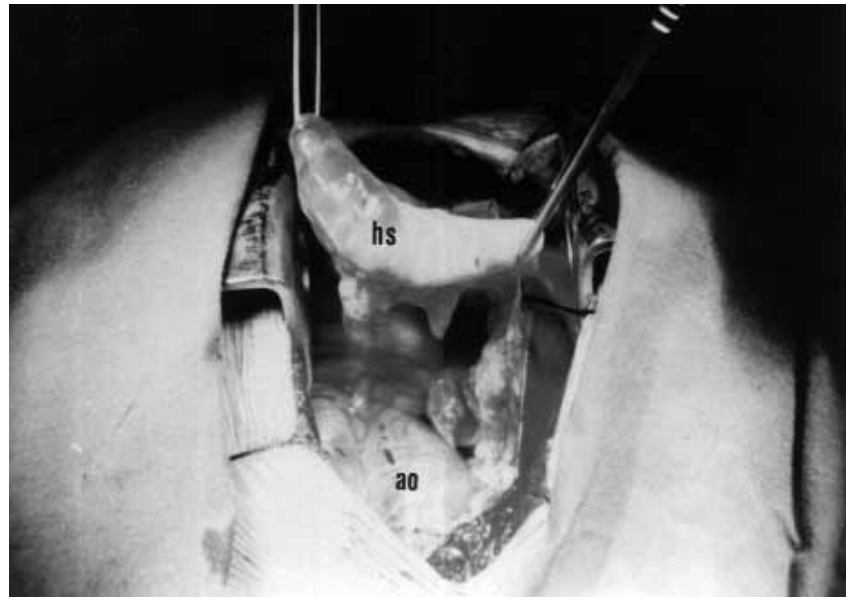

Figure 1. Surgeon's view of the aortic arch (ao) and the true hernia sac (hs).

abdominal organs were repositioned after general anesthesia had been deepened, and the defect was closed with a polytetrafluoroethylene patch. ${ }^{*}$ The patient had an uneventful recovery and has made good progress on subsequent follow-up. After the operation, the patient stated that he had had no gastrointestinal complaints, such as bloating or constipation, preoperatively, nor any history of trauma.

\section{Discussion}

Congenital diaphragmatic hernia is a highly lethal condition, especially in the newborn period. ${ }^{3}$ Weakness or partial or total absence of a region of the diaphragm may permit the abdominal contents to herniate into the thorax. These hernias differ from hiatal hernias only insofar as the defect in the diaphragm does not involve the hiatal orifice. The hernia wall in these lesions is most often composed only of peritoneum and pleura. Usually the stomach or small intestine and even a portion of the liver herniates as well. ${ }^{4}$

Sometimes these hernias are asymptomatic and are discovered only by radiography or by the identification of the intestinal sounds within the chest. Large protrusions, particularly in infants, may lead to respiratory embarrassment or vomiting. ${ }^{3}$ Herniation in the pericardial cavity, which is extremely uncommon, has been reported to produce cardiac compression, tamponade, respiratory distress, and pericardial effusions. ${ }^{5}$ There are 2

${ }^{*}$ W. L. Gore \& Associates, Inc, Flagstaff, Ariz. 
reported cases of intrapericardial congenital diaphragmatic hernia in the newborn period with an ostium secundum ASD, which resulted in severe episodic cyanosis, although there was normal pulmonary vascular resistance. ${ }^{1}$ Episodic right-to-left shunting occurred in these cases as a result of intrapericardial diaphragmatic hernial compression in the area of the tricuspid valve at the right atrioventricular groove.

Our case represents an intrapericardial diaphragmatic hernia through a $1-\mathrm{cm}$ defect remaining asymptomatic for many years. We could find no history of trauma or preoperative symptoms and physical findings resembling diaphragmatic hernia. The problem was not diagnosed until a cardiac operation was performed for ASD closure. The presence of the abdominal contents in the pericardium was a surprise to the surgeon.

\section{References}

1. Shely WW, Loitz RD, Fox AH, Wells WJ. Intrapericardial diaphragmatic hernia, atrial septal defect, and severe episodic cyanosis. Ann Thorac Surg. 1994;57:1651-3.

2. Stolf NAG, Groppo AA, Santos GG, Haddad VLS, Avelar SF Jr. Hernia difragmatica intrapericardica associada a communicaçao interatrial. Arq Bras Cardiol. 1991;57:395-7.

3. Connors RH, Weber TR, Randolph JG. The diaphragm: developmental, traumatic, and neoplastic disorders: In: Baue AE, editor. Glenn's thoracic and cardiovascular surgery. Vol 1, 5th ed. East Norwalk (CT): Appleton \& Lange; 1991. p. 532-8.

4. Robbins SL, Cotran RS, editors. Pathologic basis of disease. 2nd ed. Philadelphia: WB Saunders; 1979. p. 930

5. De Fonseca JMB, Davies MRQ, Bolton KD. Congenital hypopericardium associated with the herniation of part of the liver into the pericardial sac. J Pediatr Surg. 1987;22:851-3. 